\title{
Intergeneric Relationships within the Early-Diverging Angiosperm Family Nymphaeaceae Based on Chloroplast Phylogenomics
}

\author{
Dingxuan He ${ }^{1,2,+} \mathbb{C}$, Andrew W. Gichira ${ }^{1,3,4,+}$, Zhizhong Li ${ }^{1,3}$, John M. Nzei ${ }^{1,3,4} \mathbb{C}$, \\ Youhao Guo ${ }^{5}$, Qingfeng Wang ${ }^{1,4}$ and Jinming Chen ${ }^{1, *(\mathbb{D})}$ \\ 1 Key Laboratory of Aquatic Botany and Watershed Ecology, Wuhan Botanical Garden, \\ Chinese Academy of Sciences, Wuhan 430074, China; hdxmusic@whu.edu.cn (D.H.); \\ andrewgichira@gmail.com (A.W.G.); lizhizhong@wbgcas.cn (Z.L.); johnmulinge5@gmail.com (J.M.N.); \\ qfwang@wbgcas.cn (Q.W.) \\ 2 School of Biological and Pharmaceutical Engineering, Xinyang Agriculture and Forestry University, \\ Xinyang 464000, China \\ 3 University of Chinese Academy of Sciences, Beijing 100049, China \\ 4 Sino-Africa Joint Research Center, Chinese Academy of Sciences, Wuhan 430074, China \\ 5 Laboratory of Plant Systematics and Evolutionary Biology, College of Life Sciences, Wuhan University, \\ Wuhan 430072, China; yhguo@whu.edu.cn \\ * Correspondence: jmchen@wbgcas.cn; Tel.: +86-27-8770-0881; Fax: +86-27-8770-0802 \\ + These authors contributed equally to this work.
}

Received: 2 November 2018; Accepted: 23 November 2018; Published: 28 November 2018

\begin{abstract}
The order Nymphaeales, consisting of three families with a record of eight genera, has gained significant interest from botanists, probably due to its position as a basal angiosperm. The phylogenetic relationships within the order have been well studied; however, a few controversial nodes still remain in the Nymphaeaceae. The position of the Nuphar genus and the monophyly of the Nymphaeaceae family remain uncertain. This study adds to the increasing number of the completely sequenced plastid genomes of the Nymphaeales and applies a large chloroplast gene data set in reconstructing the intergeneric relationships within the Nymphaeaceae. Five complete chloroplast genomes were newly generated, including a first for the monotypic Euryale genus. Using a set of 66 protein-coding genes from the chloroplast genomes of 17 taxa, the phylogenetic position of Nuphar was determined and a monophyletic Nymphaeaceae family was obtained with convincing statistical support from both partitioned and unpartitioned data schemes. Although genomic comparative analyses revealed a high degree of synteny among the chloroplast genomes of the ancient angiosperms, key minor variations were evident, particularly in the contraction/expansion of the inverted-repeat regions and in RNA-editing events. Genome structure, and gene content and arrangement were highly conserved among the chloroplast genomes. The intergeneric relationships defined in this study are congruent with those inferred using morphological data.
\end{abstract}

Keywords: basal angiosperms; chloroplast; comparative genomics; Nymphaeales; Nymphaeaceae; phylogenomics; water lily

\section{Introduction}

Considerable effort has been put into divulging the evolutionary origin of Angiosperms and, subsequently, significant progress has been made over the years [1-8]. The order Nymphaeales is currently considered as one of the early-diverging clades of Angiosperms, being the second group after Amborellales [2,4,9-11]. The circumscription of Nymphaeales varies from two families, Nymphaeales 
and Cabombaceae [12-14], to three families $[15,16]$. When included in the Nymphaeales, Hydatellaceae has been recognized as a sister to Nymphaeaceae [17].

Advances in molecular methodologies, especially the use of combined datasets, have led to significant strides towards attaining strongly resolved monophyletic clades within the three families of Nymphaeales. Cabombaceae is monophyletic, comprising of two genera, Cabomba and Brasenia, with strong support from both morphological and molecular datasets [17-20]. The twelve species of the Hydatellaceae family were initially placed into two genera, Hydatella and Trithuria [16], but were later combined into a single genus based on their reproductive characters and other morphological synapomorphies [21]. Uncertainties, however, exist concerning the monophyletic nature of Nymphaeaceae, more so in relation to the position of the Nuphar genus. This is despite the numerous studies aiming at reconstructing the phylogenetic relationships within the family.

Nymphaeaceae comprises of ca. 70 species that are classified under five genera [22], including Nuphar ( 12), Barclaya ( 4), Euryale (1), Victoria (2), and the largest and paraphyletic Nymphaea ( $\sim 50$ species). Phylogenetic analysis conducted on Nymphaeales, using fast evolving and noncoding chloroplast markers, weakly supported the monophyly of Nymphaeaceae and suggested several alternatives for the placement of Nuphar [19]. In another study, a combined approach of gene tree and species tree, based on a dataset of matK and ITS2, failed to give convincing support on the monophyly of the Nymphaeaceae family [17]. A more recent study [18] that analyzed 77 protein-encoded chloroplast genes, provided further compelling support to the monophyletic clades of Hydatellaceae and Cabombaceae. The study suggested alternative scenarios that placed Nuphar at varying positions, including as a sister clade to Cabombaceae and as a sister to a clade containing both Nymphaeaceae and Cabombaceae, which depicted Nymphaeaceae as paraphyletic.

The advancements made in DNA sequencing have accelerated the sequencing of chloroplast genomes [23] while the rapid progress in bioinformatics e.g., in [24] has facilitated downstream analyses of the generated sequences. Plastid genomes, compared to nuclear genomes, are relatively smaller and are abundantly present in a single cell, making it easier to extract, sequence, and fully annotate. Chloroplast genomes have low rates of nucleotide substitutions, they lack recombination, and mostly follow a non-Mendelian inheritance, making them more preferable for elucidating evolutionary relationships. In Nymphaeales, the mode of inheritance of the chloroplast DNA is exclusively uniparental. The prospective of chloroplast phylogenomics to resolve contentious phylogenetic relationships, at nearly all taxonomic levels, has been proven over the recent past, e.g., in providing strong support for the evolutionary clades of the basal Angiosperms [4,7], the early-diverging eudicots $[8,25]$, and the early-diverging monocots [6]. Furthermore, through comparative phylogenomics, the availability of complete chloroplast genome sequences have significantly contributed to our understanding of genome evolutionary patterns driven by events such as gene transfers, duplications, and rearrangements $[23,26]$.

Based on the most recent insights by Gruenstaeudl et al. [18], few species of the order Nymphaeales, only eight from four genera of Nymphaeaceae, have their complete chloroplast genomes sequenced. Increasing the number of taxa would significantly improve phylogenetic resolutions within Nymphaeaceae. In addition to an increased number of taxa, the choice of an outgroup is equally essential in resolving taxonomic relationships. In order to avoid long-branch artifacts and providing ambiguous inferences, the chosen outgroup should not be distantly related to the ingroup [27]. This study aimed at: (1) completely sequencing the plastid genomes of five Nymphaeaceae species; (2) characterizing the newly generated chloroplast genomes and examine codon usage, repeat sequences, and RNA-editing tendencies within Nymphaeaceae, (3) identifying the ideal rooting group and using it to, (4) elucidate the phylogenetic position of Nuphar and delimit intergeneric relationships within Nymphaeaceae family. 


\section{Results}

\subsection{Structure and Gene Content of the Chloroplast Genomes}

After discarding low-quality reads and sequence adaptors, 31,494,464-40,202,250 (99.82-99.94\%) clean reads of $150 \mathrm{bp}$ were generated for the newly sequenced species of Nymphaeaceae. The total length of the chloroplast genome sequence ranged from 159,930 bp in E. ferox to 160,858 bp in N. longifolia (Table 1, Figure 1). Identical to a majority of terrestrial plants, each of the five chloroplast genomes had two single copies of unequal length; a large single copy (LSC) and a small single copy (SSC), flanked by two equal inverted-repeat (IR) regions. Nucleotide composition with a GC content of $39.1 \%$ was nearly identical in all chloroplast genomes (Table 1).
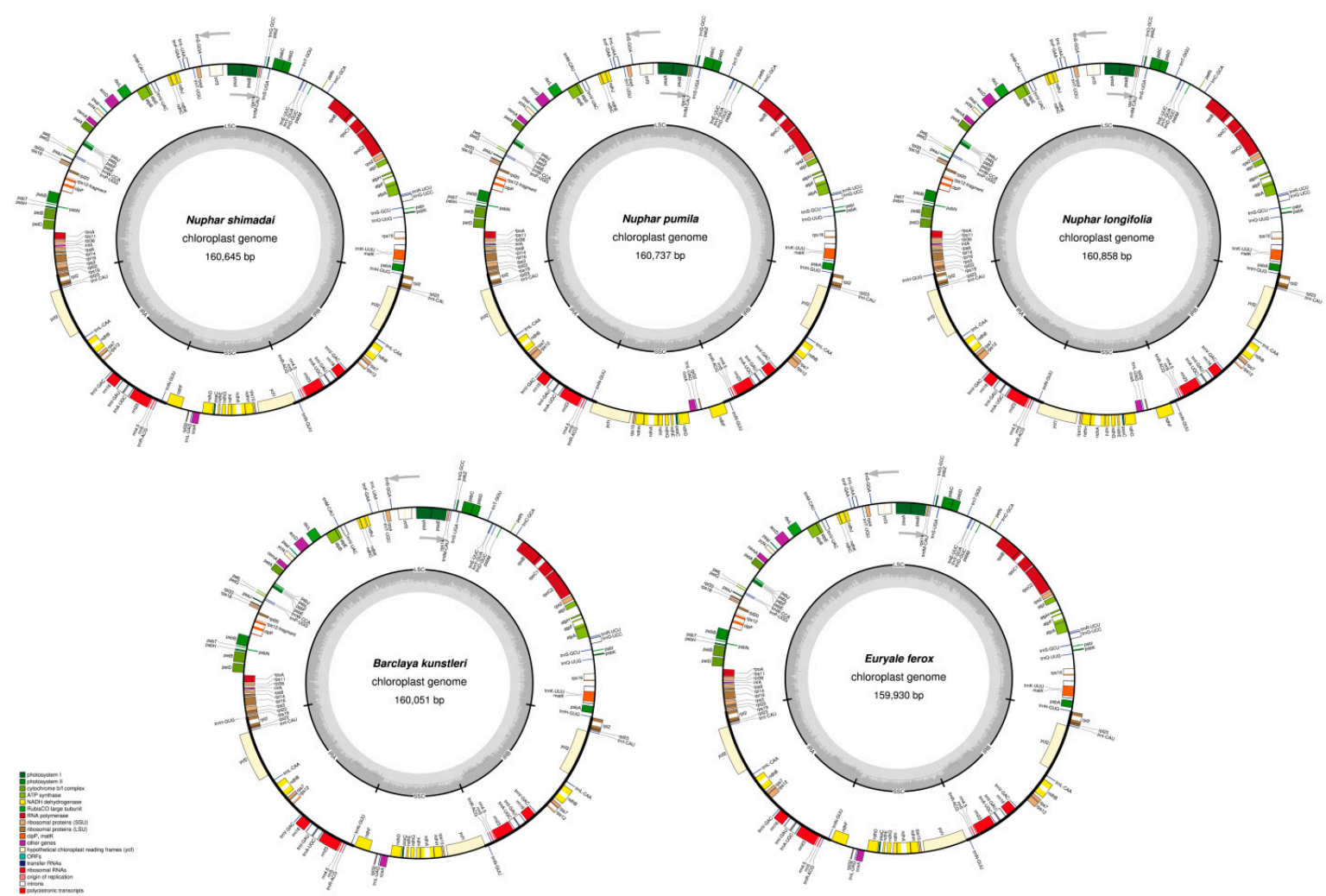

Figure 1. Circular gene maps of five chloroplast genomes of Nymphaeaceae. Grey arrows indicate the direction in which genes are transcribed. Color codes indicates the various gene functional groups, and the grey-shaded part in the inner circle shows the GC level of each chloroplast genome.

A total of 113 unique genes were annotated in each of the newly reported chloroplast genomes, out of which 79 were protein-coding, 30 were transfer RNA, while four genes coded for the ribosomal RNAs (Table 2). In four of the species, 17 genes, including six PCGs, seven tRNAs, and four rRNAs, were wholly duplicated in the inverted-repeat regions. In N. longifolia, an extra gene, trnH-GUG, was located in the IRa region and was, therefore, entirely duplicated on IRb. In N. pumila, N. shimadai, and B. kunstleri, gene trnH-GUG was located at the IRb/LSC junction; thus, only a few base pairs of its $3^{\prime}$ end were duplicated in IRb. The coding region of 18 PCGs and tRNA genes was interrupted by either one or two introns (Table 2). The rps12 gene has its 5' exon in the LSC region, while two $3^{\prime}$ exons are duplicated in the IR region; thus, it was presumed to require trans-splicing during RNA processing. 
Table 1. Characteristics of chloroplast genomes of five species of Nymphaeaceae.

\begin{tabular}{|c|c|c|c|c|c|}
\hline Name of Organism & Barclaya kunstleri & $\begin{array}{l}\text { Euryale ferox } \\
\text { Salisb. }\end{array}$ & $\begin{array}{l}\text { Nuphar longifolia } \\
\text { (Michx.) Sm. }\end{array}$ & $\begin{array}{l}\text { Nuphar pumila } \\
\text { (Timm) DC. }\end{array}$ & $\begin{array}{c}\text { Nuphar shimadai } \\
\text { Hayata }\end{array}$ \\
\hline GenBank accession number & KY392762 & KY392765 & MH050795 & MH050796 & MH050797 \\
\hline Genome size $(b p)$ & 160,051 & 159,930 & 160,858 & 160,737 & 160,645 \\
\hline Large single copy (LSC) length (bp) & 90,026 & 89,677 & 90,375 & 90,610 & 90,551 \\
\hline Small single copy (SSC) length (bp) & 19,325 & 20,201 & 18,811 & 18,865 & 18,830 \\
\hline Inverted repeat (IR) length (bp) & 25,350 & 25,026 & 25,836 & 25,631 & 25,632 \\
\hline Number of genes & 113 & 113 & 113 & 113 & 113 \\
\hline Number of protein-coding genes (duplicated in IR) & $79(6)$ & $79(6)$ & $79(6)$ & $79(6)$ & $79(6)$ \\
\hline Number of tRNA genes (duplicated in IR) & $30(7)$ & $30(7)$ & $30(8)$ & $30(7)$ & $30(7)$ \\
\hline Number of rRNA genes (duplicated in IR) & $4(4)$ & $4(4)$ & $4(4)$ & $4(4)$ & $4(4)$ \\
\hline Number of genes with one intron (two introns) & $15(3)$ & $15(3)$ & $15(3)$ & $15(3)$ & $15(3)$ \\
\hline Proportion of coding to noncoding regions & 0.68 & 0.68 & 0.69 & 0.68 & 0.69 \\
\hline Average gene density (genes/kb) & 0.82 & 0.82 & 0.83 & 0.82 & 0.82 \\
\hline GC content $(\%)$ & 39.1 & 39.1 & 39.1 & 39.1 & 39.1 \\
\hline
\end{tabular}


Table 2. List of genes encoded in each of the five chloroplast genomes of Nymphaeaceae.

\begin{tabular}{|c|c|c|c|c|c|c|c|c|}
\hline Category & Gene Type & & & & Gene & & & \\
\hline \multirow[t]{12}{*}{ Self-replication } & Ribosomal RNA & $\operatorname{rrn} 16$ & $r r n 23$ & $r r n 4.5$ & $r r n 5$ & & & \\
\hline & Transfer RNA & $\operatorname{trn} A-U G C^{*}$ & $\operatorname{trnfM-CAU}$ & $\operatorname{trnI-GAU}{ }^{*}$ & $\operatorname{trnM-CAU}$ & $\operatorname{trnR}-A C G$ & $\operatorname{trnS}-U G A$ & \\
\hline & & $\operatorname{trn} C-G C A$ & trnG-GCC & trnK-UUU * & $\operatorname{trnN}-G U U$ & $\operatorname{trnW}-C C A$ & trnT-GGU & \\
\hline & & trnD-GUC & $\operatorname{trn} G-U C C^{*}$ & $\operatorname{trnL-CAA}$ & $\operatorname{trn} Y-G U A$ & $\operatorname{trnR}-U C U$ & $\operatorname{trnT-UGU}$ & \\
\hline & & trnE-UUC & $\operatorname{trnH}-G U G$ & $\operatorname{trnL-UAA}$ * & $\operatorname{trn} P-U G G$ & $\operatorname{trnS-GCU}$ & $\operatorname{trn} V-G A C$ & \\
\hline & & $\operatorname{trnF-GAA}$ & trnI-CAU & $\operatorname{trnL-UAG}$ & $\operatorname{trn} Q-U U G$ & $\operatorname{trnS}-G G A$ & $\operatorname{trn} V-U A C^{*}$ & \\
\hline & Small ribosomal units & rps11 & rps12 & rps14 & rps15 & $r p s 16^{*}$ & $r p s 18$ & \\
\hline & & rps19 & rps2 & rps3 & rps4 & rps7 & rps 8 & \\
\hline & Large ribosomal units & rpl14 & rpl16 & $r p l 2 *$ & $r p l 20$ & rpl22 & rpl23 & rpl32 \\
\hline & & rpl33 & rpl36 & & & & & \\
\hline & RNA polymerase subunits & rpoA & rpoB & $r p o C 1 *$ & rpoC2 & & & \\
\hline & translation initiation factor & $\operatorname{infA}$ & & & & & & \\
\hline \multirow[t]{8}{*}{ Photosynthesis genes } & NADH dehydrogenase & $n d h A^{*}$ & $N d h B^{*}$ & $n d h C$ & $n d h D$ & $n d h E$ & $n d h F$ & \\
\hline & & $n d h G$ & $n d h H$ & $n d h I$ & $n d h J$ & $n d h K$ & & \\
\hline & photosystem I & $p s a A$ & $p s a B$ & psaC & psaI & psaJ & $y c f 3^{* *}$ & $y c f 4$ \\
\hline & & $p s b A$ & $p s b B$ & $p s b C$ & $p s b D$ & $p s b E$ & $p s b F$ & psbH \\
\hline & photosystem II & psbI & $p s b J$ & $p s b K$ & $p s b L$ & $p s b M$ & $p s b N$ & psbT \\
\hline & cytochrome b/f complex & pet $A$ & $\operatorname{pet} B$ & petD & $\operatorname{pet} G$ & pet $L$ & $\operatorname{pet} N$ & \\
\hline & ATP synthase & $\operatorname{atp} A$ & $\operatorname{atpB}$ & atpE & $\operatorname{atpF} F^{*}$ & $\operatorname{atpH}$ & atpI & \\
\hline & Large subunit of rubisco & $r b c L$ & & & & & & \\
\hline \multirow[t]{6}{*}{ Other genes } & Maturase & matK & & & & & & \\
\hline & Protease & $\operatorname{clp} P^{* *}$ & & & & & & \\
\hline & Acetyl-CoA-carboxylase sub-unit & $a c c D$ & & & & & & \\
\hline & Envelope membrane protein & $\operatorname{cem} A$ & & & & & & \\
\hline & Component of TIC complex & $y c f 1$ & & & & & & \\
\hline & c-type cytochrome synthesis & $\operatorname{ccs} A$ & & & & & & \\
\hline Unknown & hypothetical genes reading frames & $y c f 2$ & & & & & & \\
\hline
\end{tabular}

Notes: the ${ }^{*}$ and ${ }^{* *}$ symbols indicate genes with one and two intron(s) respectively. 


\subsection{Codon-Usage, RNA-Editing, and Repetitive-Sequence Analyses}

Slight variations were observed in the usage of codons in all the analyzed species of Nymphaeaceae. Seventy-nine protein-coding genes in each of the chloroplast genomes, encoded between 26,126 and 26,378 codons (Table S2). In all the species, the amino acid leucine was encoded by the highest number of codons, ranging from 2669 in N. pumila to 2698 in N. jamesoniana. Cysteine was encoded by the least number of codons varying from 302 in the three newly reported species of Nuphar to 314 in B. longifolia and N. advena. As is normally the case with most angiosperms, only two codons, AUG for Methionine and UGG for Tryptophan, were used without any bias (relative synonymous codon usage $(R S C U)=1$ ). The selection and usage of stop codons was biased in favor of TAA (RSCU > 1). The codons with A or $\mathrm{T}$ at their third positions were highly preferred to those with a $\mathrm{C}$ or G. In this regard, codon ATT for amino acid isoleucine (average 1023.58) had the highest count. Out of the 64 codons, 31 had RSCU values of more than 1 ; an indication that they were frequently used. The average number and RSCU for each codon was calculated for all 12 species (Figure 2; Table S2). The common initiation codon was ATG, although deviations were observed within some species, where GTG was noted in genes rpoc1, cemA, and rps19, while $p s b L$ and $n d h D$ had ACG as the first codon.

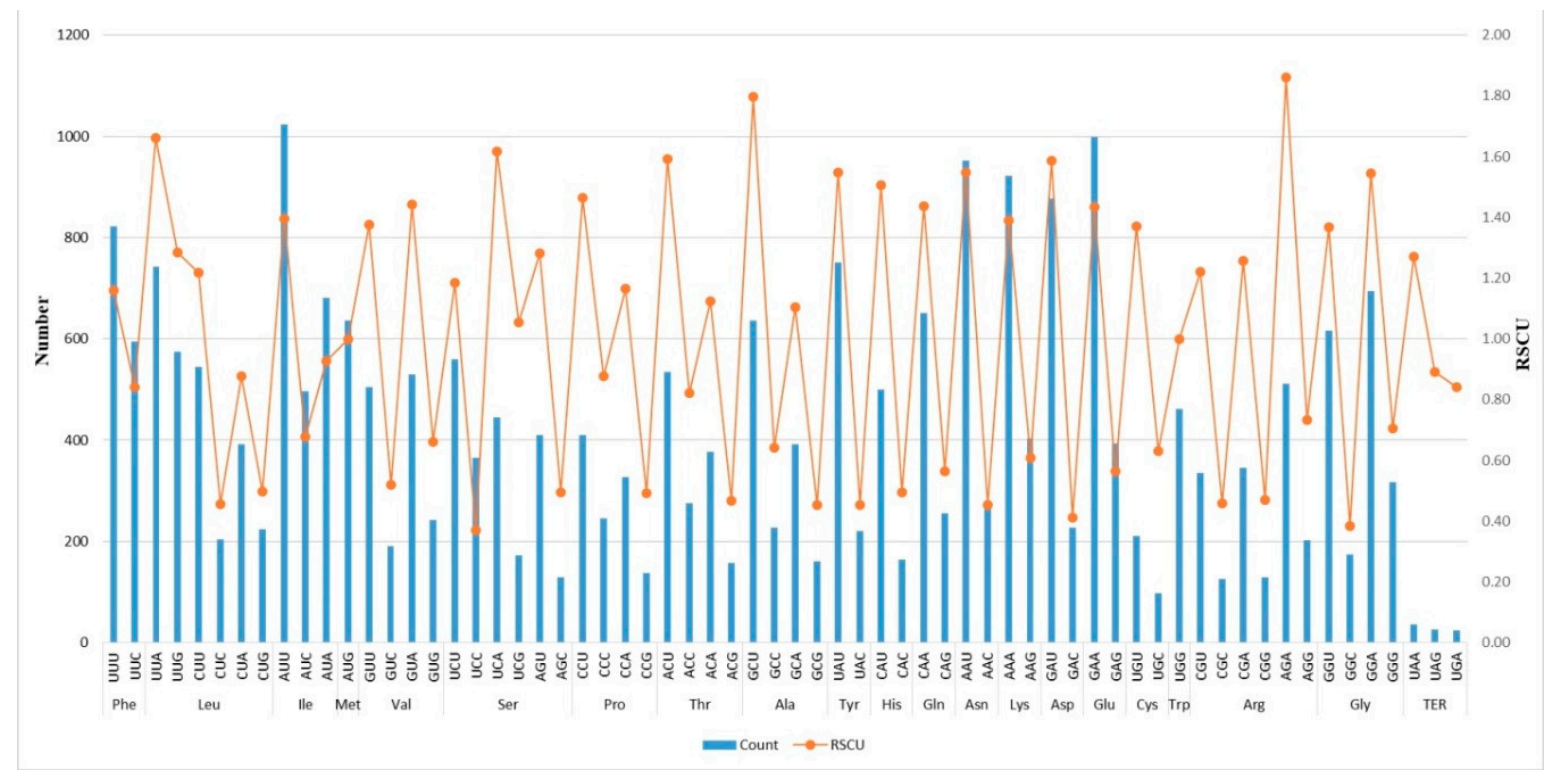

Figure 2. Details of codon preferences (bar) and relative synonymous codon usage values (line) of 12 chloroplast genomes of Nymphaeaceae.

Potential RNA-editing sites were detected in between 24 and 28 protein-coding genes (Table 3; Table S3). All RNA-editing sites reported here were of the $\mathrm{C}$ to $\mathrm{U}$ type, the majority of which affected a single site, either the first or the second position of a given codon. However, in some genes, e.g., ccs $A$ and $r p o C 1$, only the third position was conserved in some codons. A total of 19 genes were commonly affected in each of the genomes. Out of these, $r p o C 2, n d h A, n d h B$, and $n d h D$ had the highest number of editing sites in each genome (Figure 3). In order to test for correlation between RNA-editing events and phylogenetic relationships, we used the details of the 19 common genes to create a binary data matrix that was then used to construct a UPGMA dendrogram in MEGA7 software (Figure S1). 


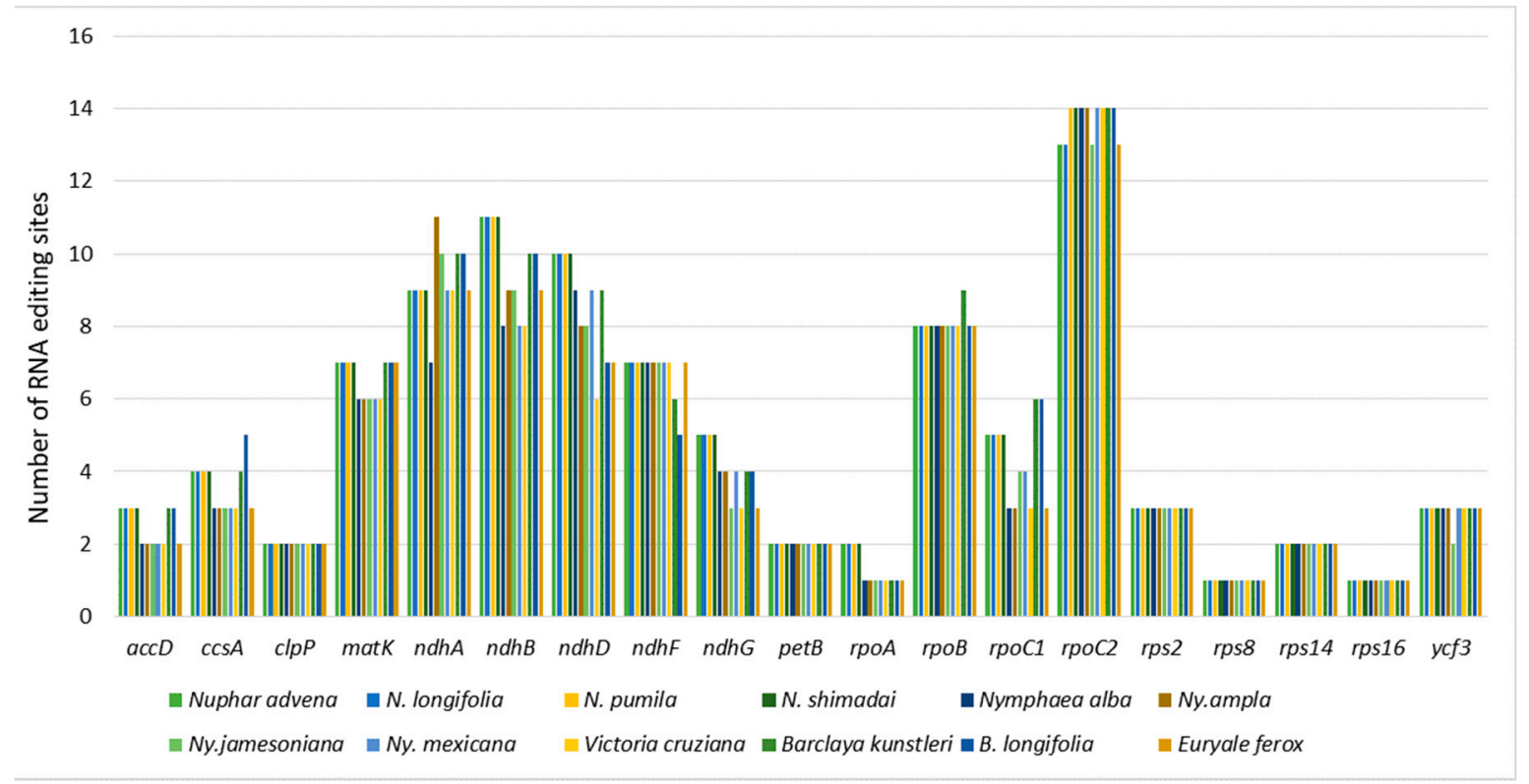

Figure 3. Number of RNA-editing sites in each of the transcripts of 19 common genes in all analyzed chloroplast genomes.

A total of 438 short tandem repeats were mined in 12 species of Nymphaeaceae. The number of repeats in each chloroplast genome varied from 19 (N. jamesoniana) to 58 (N. shimadai). Interestingly, each species of Nuphar had a high number of repeats $(>50)$, followed by the Barclaya species $(>30)$. The majority of the microsatellites were A-T rich homopolymers, which was a common observation across all species except in $N$. jamesoniana, which had two strings of polyC (C10) and only one polyT (T13). Noncoding regions possessed more simple-sequence repeats (SSRs) compared to the coding regions. The repeat motif, length, and the location of the microsatellites are shown in Table S4. In addition, a total of 128 long tandem repeats were discovered in the 12 chloroplast genomes. Forty-nine repeats were found in the genome of E. ferox, which was the highest number of repeats in a single genome. Other genomes had between 12, in N. pumila, and one, in B. longifolia. Forward repeats exhibited a large percentage $(80.5 \%)$, with the rest being the palindromic repeat sequences (Table S4).

\subsection{Inverted Repeats and Genome Comparison}

Gene positioning at the IR/SSC junctions was stable, in that the JSA boundary expanded into the $y c f 1$ gene in all species at varying lengths, while the $n d h F$ gene was squarely located in the IR, leaving a gap of varying length between JLB and the $3^{\prime}$ end of the gene. However, in all species of Nuphar, the JLB expanded into the $n d h F$ gene, resulting in an overlap of 11 to $12 \mathrm{bp}$ between the $n d h F$ and the ycf1 pseudogene and a relatively smaller SSC region compared to the other species. Significant variations were observed at the JLA and JLB junctions (Figure 4). Whole genome alignments, using Mauve, revealed well-conserved chloroplast genomes that lacked major inversions or rearrangements. Gene content and order were highly maintained and, thus, only three locally collinear blocks were identified among the species of Nymphaeaceae (Figure 5). 
Table 3. List of protein-coding genes affected by RNA editing in each of the 12 chloroplast genomes of Nymphaeaceae.

\begin{tabular}{|c|c|c|c|c|c|c|c|c|c|c|c|}
\hline $\begin{array}{l}\text { Nuphar } \\
\text { advena }\end{array}$ & $\begin{array}{l}\text { Nuphar } \\
\text { longifolia }\end{array}$ & $\begin{array}{l}\text { Nuphar } \\
\text { pumila }\end{array}$ & $\begin{array}{l}\text { Nuphar } \\
\text { shimadai }\end{array}$ & $\begin{array}{c}\text { Nymphaea } \\
\text { alba }\end{array}$ & $\begin{array}{l}\text { Nymphaea } \\
\text { ampla }\end{array}$ & $\begin{array}{c}\text { Nymphaea } \\
\text { jamesoniana }\end{array}$ & $\begin{array}{l}\text { Nymphaea } \\
\text { mexicana }\end{array}$ & $\begin{array}{l}\text { Victoria } \\
\text { cruziana }\end{array}$ & $\begin{array}{l}\text { Euryale } \\
\text { ferox }\end{array}$ & $\begin{array}{l}\text { Barclaya } \\
\text { kunstleri }\end{array}$ & $\begin{array}{l}\text { Barclaya } \\
\text { longifolia }\end{array}$ \\
\hline$a c c D^{3}$ & $a c c D^{3}$ & $a c c D^{3}$ & $a c c D^{3}$ & $a c c D^{2}$ & $a c c D^{2}$ & $a c c D^{2}$ & $a c c D^{2}$ & $a c c D^{2}$ & $a c c D^{2}$ & $a c c D^{3}$ & $a c c D^{3}$ \\
\hline \multirow[t]{3}{*}{$\operatorname{atp} A$} & $\operatorname{atp} A$ & $\operatorname{atp} A$ & $\operatorname{atp} A$ & AtpA & & $\operatorname{atp} A$ & $\operatorname{atp} A$ & $\operatorname{atp} A$ & $\operatorname{atp} A$ & $\operatorname{atp} A$ & $\operatorname{atp} A$ \\
\hline & & & & atpB & $\operatorname{atpB}$ & $\begin{array}{l}\operatorname{atpB} \\
\operatorname{atpF}\end{array}$ & $a t p B$ & atpB & atpB & atpB & $\operatorname{atpB}$ \\
\hline & $\csc ^{4}$ & $\csc ^{4}$ & 4 & atpI & atpI & atpI & atpI & atpI & atpI & atpI & atpI \\
\hline $\operatorname{clp} P^{2}$ & $\operatorname{clpP} P^{2}$ & $\operatorname{clpP} P^{2}$ & $\operatorname{clpP} P^{2}$ & $\operatorname{clp} P^{2}$ & $\operatorname{clp} P^{2}$ & $\operatorname{clp} P^{2}$ & $\operatorname{clpP} P^{2}$ & $\operatorname{clp} P^{2}$ & $\operatorname{clp} P^{2}$ & $\operatorname{clpP} P^{2}$ & $\operatorname{clpP} P^{2}$ \\
\hline mat $^{7}$ & matK $^{7}$ & matK $^{7}$ & matK $^{7}$ & matK $^{6}$ & matK $^{6}$ & matK $^{6}$ & $\operatorname{mat}^{6}$ & matK $^{6}$ & matK $^{7}$ & matK $^{7}$ & matK $^{7}$ \\
\hline$n d h A^{9}$ & $n d h A^{9}$ & $n d h A^{9}$ & $n d h A^{9}$ & $n d h A^{7}$ & $n d h A^{11}$ & $n d h A^{10}$ & $n d h A^{9}$ & $n d h A^{9}$ & $n d h A^{9}$ & $n d h A^{10}$ & $n d h A^{10}$ \\
\hline$n d h B^{11}$ & $n d h B^{11}$ & $n d h B^{11}$ & $n d h B^{11}$ & $n d h B^{8}$ & $n d h B^{9}$ & $n d h B^{9}$ & $n d h B^{8}$ & $n d h B^{8}$ & $n d h B^{9}$ & $n d h B^{10}$ & $n d h B^{10}$ \\
\hline$n d h D^{10}$ & $n d h D^{10}$ & $n d h D^{10}$ & $n d h D^{10}$ & $n d h D^{9}$ & $n d h D^{8}$ & $n d h D^{8}$ & $n d h D^{9}$ & $n d h D^{6}$ & $n d h D^{7}$ & $n d h D 9$ & $n d h D^{7}$ \\
\hline$n d h F^{7}$ & $n d h F^{7}$ & $n d h F^{7}$ & $n d h F^{7}$ & $n d h F^{7}$ & $n d h F^{7}$ & $n d h F^{7}$ & $n d h F^{7}$ & $n d h F^{7}$ & $n d h F^{7}$ & $n d h F^{6}$ & $n d h F^{5}$ \\
\hline$n d h G^{5}$ & $n d h G^{5}$ & $n d h G^{5}$ & $n d h G^{5}$ & $n d h G^{4}$ & $n d h G^{4}$ & $n d h G^{3}$ & $n d h G^{4}$ & $n d h G^{3}$ & $n d h G^{3}$ & $n d h G^{4}$ & $n d h G^{4}$ \\
\hline petB ${ }^{2}$ & petB ${ }^{2}$ & $\begin{array}{l}\operatorname{pet} B^{2} \\
\operatorname{pet} D\end{array}$ & petB ${ }^{2}$ & pet $B^{2}$ & petB ${ }^{2}$ & petB ${ }^{2}$ & pet ${ }^{2}$ & pet $B^{2}$ & petB ${ }^{2}$ & petB ${ }^{2}$ & petB ${ }^{2}$ \\
\hline pet $G$ & petG & pet $G$ & pet $G$ & & & & & & & petG & petG \\
\hline$p s b E$ & $p s b E$ & $p s b E$ & $p s b E$ & & $p s b E$ & $p s b E$ & $p s b E$ & $p s b E$ & $p s b E$ & $p s b E$ & $p s b E$ \\
\hline$p s b F$ & $p s b F$ & $p s b F$ & $p s b F$ & & & & & & & $p s b F$ & psbF \\
\hline \multirow[t]{2}{*}{$p s b L$} & $p s b L$ & & & $p s b L$ & $p s b L$ & $p s b L$ & $p s b L$ & $p s b L$ & $p s b L$ & psbL & $p s b L$ \\
\hline & & & & $r p l 2$ & $r p l 2$ & $r p l 2$ & $r p l 2$ & $r p l 2$ & $r p l 2$ & $r p l 2$ & $r p l 2$ \\
\hline rpl20 & rpl20 & $r p l 20$ & rpl20 & rpl20 & rpl20 & rpl20 & rpl20 & rpl20 & rpl20 & rpl20 & \\
\hline$r p o A^{2}$ & $r p o A^{2}$ & $r p o A^{2}$ & $r p o A^{2}$ & $r p o A^{1}$ & $r p o A^{1}$ & $r p o A^{1}$ & $r p o A^{1}$ & $r p o A^{1}$ & $r p o A^{1}$ & $r p o A^{1}$ & $r p o A^{1}$ \\
\hline$r p o B^{8}$ & $r p o B^{8}$ & $r p o B^{8}$ & $r p o B^{8}$ & $r p o B^{8}$ & $r p o B^{8}$ & $r p o B^{8}$ & $r p o B^{8}$ & $r p o B^{8}$ & $r p o B^{8}$ & $r p o B^{8}$ & $r p o B^{8}$ \\
\hline rpoC1 ${ }^{5}$ & rpoC $^{5}$ & rpoC1 ${ }^{5}$ & rpoC $1^{5}$ & rpoC1 ${ }^{3}$ & rpoC $1^{3}$ & rpoC1 4 & rpoC1 4 & $\operatorname{rpoC}^{3}$ & rpoC1 ${ }^{3}$ & rpoC1 6 & rpoC1 ${ }^{6}$ \\
\hline rpoC2 13 & rpoC2 13 & rpoC2 14 & rpoC2 14 & rpoC2 14 & rpoC2 14 & rpoC2 13 & rpoC2 14 & rpoC2 14 & rpoC2 13 & rpoC2 14 & rpoC2 14 \\
\hline$r p s 2^{3}$ & $r p s 2^{3}$ & $r p s 2^{3}$ & $r p s 2^{3}$ & $r p s 2^{3}$ & $r p s 2^{3}$ & $r p s 2^{3}$ & $r p s 2^{3}$ & $r p s 2^{3}$ & $r p s 2^{3}$ & $r p s 2^{3}$ & $r p s 2^{3}$ \\
\hline$r p s 8^{1}$ & $r p s 8^{1}$ & $r p s 8^{1}$ & $r p s 8^{1}$ & rps $8^{1}$ & $r p s 8^{1}$ & $r p s 8^{1}$ & $\operatorname{rps} 8^{1}$ & rps $8^{1}$ & rps $8^{1}$ & $r p s 8^{1}$ & rps $8^{1}$ \\
\hline rps $14^{2}$ & $r p s 14^{2}$ & $r p s 14^{2}$ & $r p s 14^{2}$ & $r p s 14^{2}$ & $r p s 14^{2}$ & $r p s 14^{2}$ & $r p s 14^{2}$ & $r p s 14^{2}$ & $r p s 14^{2}$ & $r p s 14^{2}$ & $\operatorname{rps} 14^{2}$ \\
\hline $\operatorname{rps}^{2} 6^{1}$ & $r p s 16^{1}$ & $\operatorname{rps} 16^{1}$ & $r p s 16^{1}$ & $\operatorname{rps} 16^{1}$ & $\operatorname{rps} 16^{1}$ & $r p s 16^{1}$ & $r p s 16^{1}$ & $\operatorname{rps} 16^{1}$ & $r p s 16^{1}$ & $\operatorname{rps} 16^{1}$ & $\operatorname{rps} 16^{1}$ \\
\hline$y c f 3^{3}$ & $y c f 3^{3}$ & $y c f 3^{3}$ & $y c f 3^{3}$ & $y c f 3^{3}$ & $y c f 3^{3}$ & $y c f 3^{2}$ & $y c f 3^{3}$ & $y c f 3^{3}$ & $y c f 3^{3}$ & $y c f 3^{3}$ & $y c f 3^{3}$ \\
\hline
\end{tabular}

Note: the superscript number indicates the number of edited sites in each of the 19 protein-coding genes common in all the genomes. 


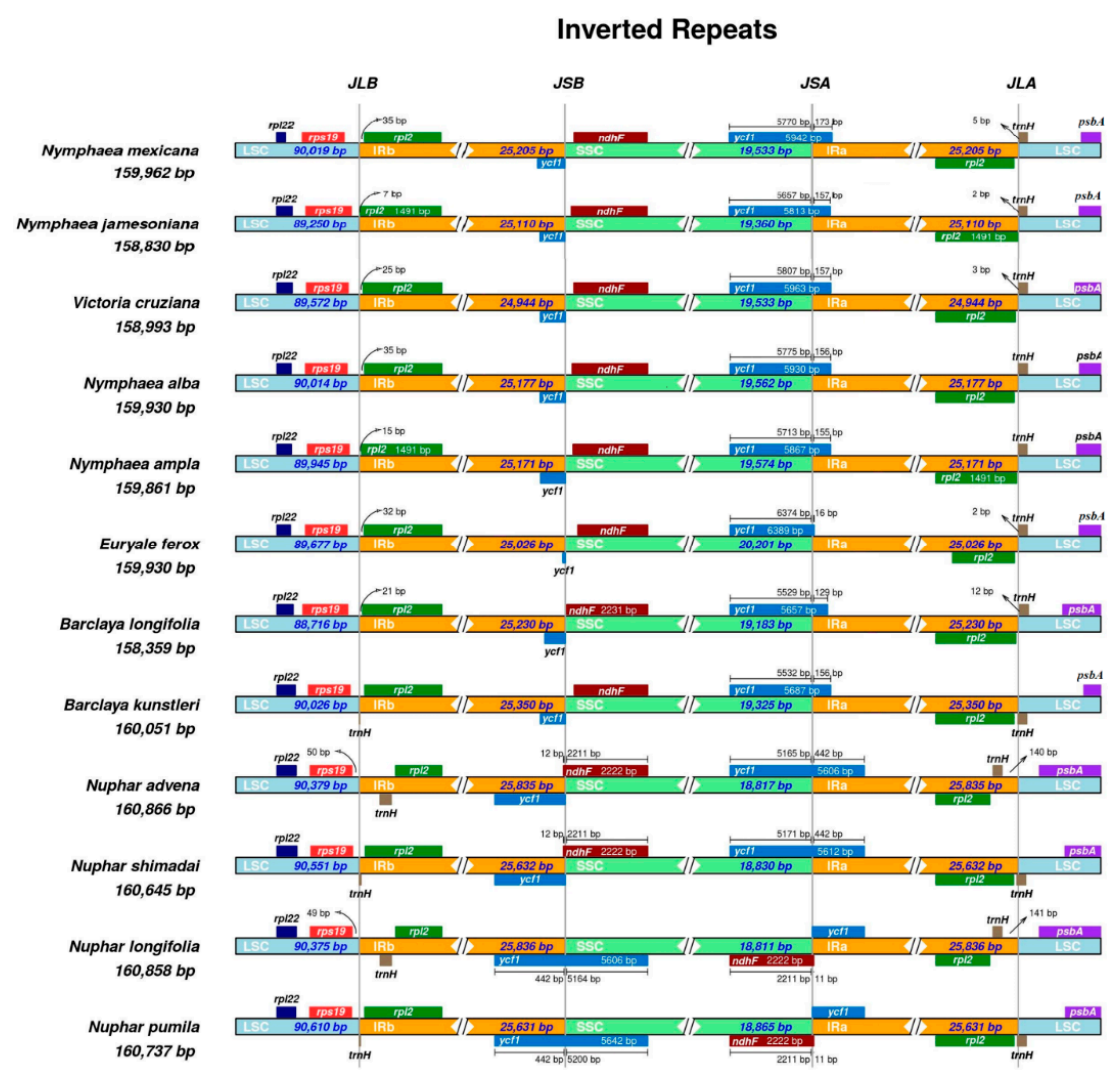

Figure 4. Comparison of the border positions of the large single copy, small single copy, and the inverted-repeat regions among chloroplast genomes of twelve species of Nymphaeaceae. Complete genes and portions of genes adjacent to the junctions are depicted by differently colored blocks.

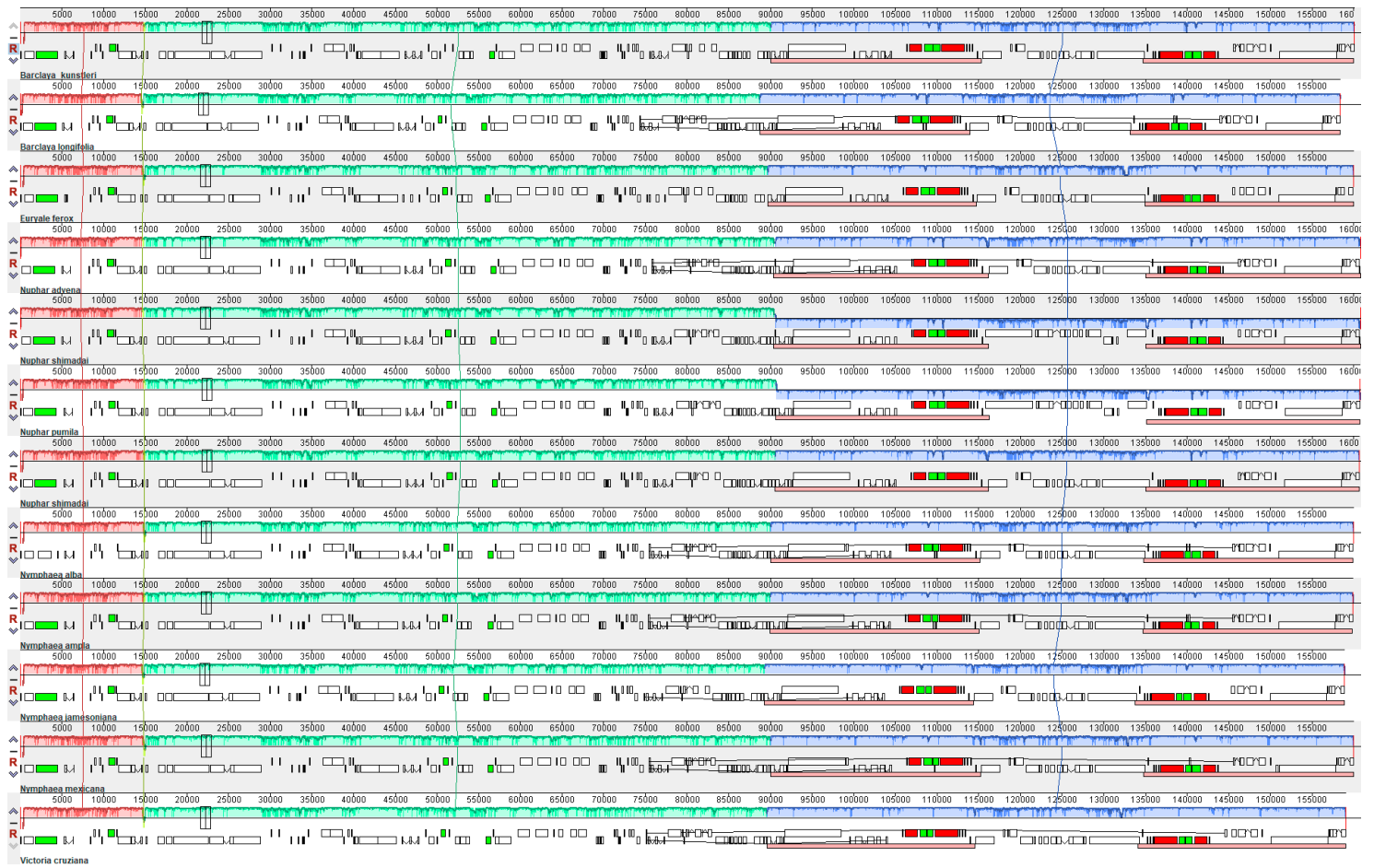

Figure 5. Mauve software alignment of the whole chloroplast genome of 12 species of Nymphaeaceae. Local collinear blocks representing identical gene clusters are depicted by the same color and are connected by lines. 


\subsection{Phylogenetic Analyses}

The 66 protein-coding gene dataset produced highly congruent topologies based on the various Maximum Likelihood (ML) and Bayesian Inference (BI) strategies, using different partitioning approaches. Using Amborella trichopoda and under a partitioned data matrix, a weakly supported clade containing Cabombaceae and four genera of Nymphaeaceae was recovered; Nuphar was positioned (strongly supported) at the base and as a sister clade (Figure S2a). Under unpartitioned data, a clade containing Nuphar as a sister to Cabombaceae was strongly supported (Figure S2b). Using Trithuria incospicua and T. filamentosa (Hydatellaceae) as outgroup in the phylogenetic analyses, the monophyly of Nymphaeaceae and Cabombaceae were strongly supported $(B S=100, P P=1.0)$ by both ML and BI phylogenetic analyses using unpartitioned and partitioned data matrix (Figure 6). The three newly generated species of Nuphar were fully supported as sisters to N. advena in a monophyletic clade. Similarly, B. kunstleri and E. ferox had full support at their respective nodes as sisters to B. longifolia and $V$. cruziana, respectively. The Nymphaea genus was strongly supported to be a paraphyletic clade in relation to E. ferox and V. cruziana.

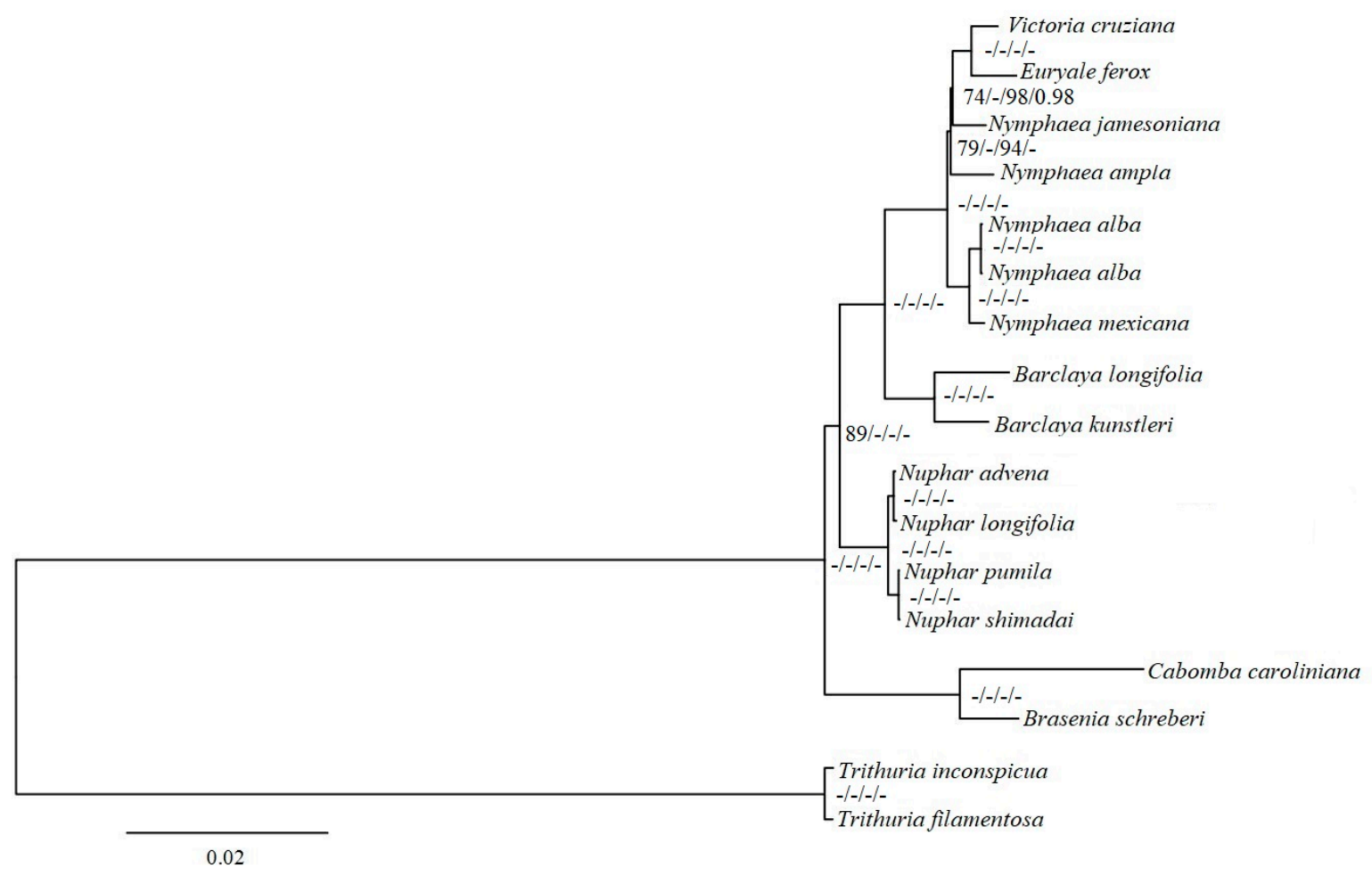

Figure 6. Phylogenetic relationships among the species of Nymphaeaceae, Cabombaceae, and Hydatellaceae (outgroup). The Maximum Likelihood (ML) and Bayesian Inference (BI) phylogenetic tree was based on 66 protein codon genes. The numbers indicate ML bootstrap support (100) and BI posterior probabilities (1.0) values. The - symbol indicates maximum support. The first two values and the last two are for unpartitioned data and partitioned data respectively.

\section{Discussion}

\subsection{Chloroplast Genome Structure}

Normally, chloroplast genomes of higher plants are highly conserved circular molecules with a size range of 120 to $160 \mathrm{~kb}$, and they typically contain 110-130 unique genes [28,29]. In this study, five recently sequenced complete chloroplast genome sequences on Nymphaeaceae were reported. These are added to the small but a steadily growing number of species whose chloroplast genomes have been reported in this family and in the Nymphaeales order. The overall structure, nucleotide 
composition, and gene content and arrangement among the reported taxa were nearly identical to each other and among those of early diverging angiosperms (Table 1 in this study, Table 1 in Gruenstaeudl et al. [18]). The genomes encoded an equal number of genes, 113 unique genes in total. The potential of the $y c f 15$ and $y c f 68$ genes to encode for protein in chloroplast genomes of basal angiosperms has previously been questioned [18,30,31]. Although sequences of the two hypothetical genes are well-preserved, partially or in whole in most of the species, studies suggest that these are not protein-coding genes and, therefore, were not annotated in the currently reported genomes. Likewise, the two open reading frames; orf 42 and orf 56 , which had been annotated in some genomes of Nymphaeaceae, were excluded in this study, based on the observation that their ability to code for proteins in Angiosperm is yet to be confirmed [18,32].

\subsection{Codon-Usage, RNA-Editing, and Repetitive-Sequence Analyses}

The genetic code in both eukaryotes and prokaryotes is degenerate and, with 61 codons encoding for only 20 amino acids, some amino acids are encoded by more than one codon [33]. Therefore, since codons are used with varying frequency, codon usage bias is generally inevitable. Codon usage is usually driven by mutational bias and natural selection [34], and the most-affected bases are usually at the third and sometimes at the second position of a codon, which was evident in the chloroplast genomes of Nymphaeaceae species. Normally, RSCU values greater than 1 indicate over-representation of a given codon, while values below 1 show less usage, and values of 1 indicate lack of bias in codon usage [35]. In each species, over 30 codons had RSCU $>1$, an indication that these were highly preferred and, as expected, all had A/T at their third position. Understanding codon-usage patterns may be effective in discerning the different evolutionary processes that affect chloroplast genomes. A well-preserved pattern of codon usage bias (CUB) was observed in all the studied species of Nymphaeaceae, which was nearly identical to those reported in other plant species [36,37].

RNA editing is typical in the chloroplast genome sequences of most land plants. The sequences are subject to regular modification at the transcript level through RNA editing and trans-splicing [38]. Thus, recognition of RNA-editing sites in transcripts is elemental for comprehending the coding patterns in chloroplast genomes. In addition, certain RNA-editing events cause divergence in the evolutionarily conserved amino acid sequences [39]. Here, we identified RNA editing sites in transcripts from each of the 12 complete chloroplast genomes of Nymphaeaceae. The number of editing sites varied slightly between 94 in V. cruziana and 108 in B. kunstleri. Although the majority of editing sites were in internal codons, the initiation codon ATG (amino acid methionine) was restored from ACG in the transcripts of genes $p s b L, n d h B$, and $r p o C 1$. There was no considerable difference in the number of genes affected by RNA editing, which varied from 24, in two species of Nuphar, to 28, in B. kunstleri. Nineteen genes were common in all the chloroplast genomes, and the majority of their editing sites were conserved. Comparative analyses have shown no correlation between RNA-editing events and phylogenetics in major groups of land plants [40]. However, in this study, further comparative analysis revealed certain patterns that are worth mentioning. For example, potential RNA-editing sites were predicted in the atpB, atpI and $r p l 2$ genes in all the genera except in Nuphar, while genes $p s b F$ and pet $G$ had no editing sites in the Nymphaea, Victoria, and Euryale clades. These patterns were also observed in the number of sites predicted in some gene transcripts, e.g., gene $a c c D$ had three editing sites in Nuphar, and only two in all the other genera. The UPGMA dendrogram, constructed based on RNA-editing events, inferred a paraphyletic Nymphaeaceae supporting Nuphar as a sister to Cabombaceae. This implied that RNA-editing events are well-conserved genus/clade-specific evolutionary processes in the chloroplast genomes of Nymphaeaceae.

Repetitive sequences play various roles in genome organization, gene activities, and DNA recombination, replication, and repair [41]. Those located in the protein-coding regions may interfere with the normal functions of proteins [42]. The majority of the tandem repeats discovered in the chloroplast genomes of Nymphaeaceae were located in the noncoding segments. Short tandem repeats were plentifully distributed within genomes. Interestingly, species of Nuphar, with the largest genome 
sizes, exhibit the largest number of SSRs compared to the other genomes. In situations where SSRs are randomly distributed, more SSRs would be identified in larger chloroplast genomes compared to the smaller ones [31]. However, a positive correlation between genome size and the number of SSRs seems elusive, because Nymphaea jamesoniana had fewer SSR repeats than the species with the smallest genome size.

\subsection{Comparative Analyses}

Comparative chloroplast genomics provides insights into the evolutionary patterns of chloroplasts [23] and lays the foundation for functional genomic and phylogenomic studies [43]. The five genomes exhibit a quadripartite structure that is distinctive from the majority of land plants. Although chloroplast genomes are highly conserved, particularly among closely related species, minor variations are evident, and perhaps the most noticeable difference is the total genome size of the various species. Species of Nymphaeaceae have so far displayed a narrow range of size disparity, with B. longifolia (158,360 bp) [18] and N. advena (160,866 bp) [31] possessing the smallest and the largest genomes, respectively. Chloroplast genomes reported in this study differed slightly in size with a difference of about $1 \mathrm{~kb}$ between the smallest and the largest. The contraction/expansion of the inverted-repeat regions is listed among the main sources of size variations in chloroplast genomes. The IRs can greatly fluctuate in size and their positions differ even among species of the same genus [44]. The Nuphar genus harbors the largest chloroplast genomes among the Nymphaeaceae species and this is as a result of increased expansion of the IRs into the SC regions. In most chloroplast genomes of nonmonocot angiosperms, the trnH-GUG and rps19 genes lie within the LSC region [44,45]. The JLA boundaries of $N$. advena and N. longifolia, the largest chloroplast genomes of Nymphaeaceae, are located upstream of $\operatorname{trnH}$-GUG gene, which is, therefore, placed within the IRa region. The positioning of the IR/SC junction in these two species of Nuphar is congruent with the reports by Wang et al. [45], who, based on the results of N. advena, made a generalized observation for the Nymphaeaceae family. However, based on the results in this study, the positioning of the JLA and JLB junctions in Nymphaeaceae are rather more divergent. Other species whose genome sizes were over $160 \mathrm{~kb}$, including N. pumila, N. shimadai, and B. kunstleri, had their IR/LSC expanded into the trnH-GUG gene, which, based on Wang et al. [45], belongs to the same category, (c), as some eudicots.

The mechanisms of expansion and contraction of the inverted-repeat regions have been shown to have evolutionary significance and could be used as sources of important molecular markers to elucidate relationships among various plant species $[45,46]$. The variations observed at the IR/LSC boundaries could be potential sources of phylogenetic markers ideal to study interfamilial relationships within Nymphaeaceae. The Mauve software combines the analysis of large-scale evolutionary events with traditional sequence alignments in order to identify conserved regions, rearrangements, and inversions in genomes [47]. The alignments revealed that the entire genome structure and gene arrangement are collinear and highly conserved within the Nymphaeaceae family. Only three locally collinear blocks were identified, which were interpreted to harbor three clusters of conserved homologous genes (Figure 5).

\subsection{Phylogenetic Inference}

Coding and noncoding regions of chloroplast genomes are subject to varying rates of molecular evolution, thus providing ample genetic variation for phylogenetic investigations at diverse taxonomic levels $[48,49]$. Phylogenetic analyses of one of the early diverging angiosperms, Nymphaeales, have been limited to the use of one or a few molecular markers obtained from plastid or nuclear genomes $[13,17,19,50]$. Consequently, they have provided important insight into the evolutionary relationship between major lineages of Nymphaeales. However, with the use of large-scale genome-wide datasets that have been made available by the rapidly increasing number of completely sequenced plastid genomes, well-resolved and strongly supported phylogenetic clades have been obtained $[4,5,7]$. The most recent phylogenetic analysis, utilizing multiple chloroplast protein-coding genes [18], strongly supported the monophyly 
of Cabombaceae and Hydatellaceae under different data partitions, but could not firmly support a monophyletic Nymphaeaceae family. In this study, more taxa of Nymphaeaceae were added to the eight used by Gruenstaeudl et al. [18]. Multigene phylogenetic analysis was conducted using 66 protein-coding genes obtained from 17 chloroplast genomes of Nymphaeales.

In spite of increased taxon sampling in Nuphar, its phylogenetic position remained vague in relation to the used outgroups. Using Amborellaceae to root the phylogenetic tree, both partitioned and unpartitioned data schemes placed Nuphar at two different positions, confirming earlier proposed hypotheses. Without data partitioning, Nuphar and Cabombaceae formed a weakly supported (44/0.5 BS/PP) clade that was sister to the rest of Nymphaeaceae, whereas, under partitioned data, Nuphar was positioned at the base, while Cabombaceae and the rest of Nymphaeaceae formed a weak (26/0.9 BS/PP) relationship (Figure S2). An outgroup provides evolutionary information, including more precise determination of pleisiomorphic traits of an ingroup [51]. Accordingly, an inappropriate choice of outgroup and limited taxon sampling may fail or give misleading phylogenetic resolutions $[30,52,53]$.

The proximity of Hydatellaceae to the ingroup, containing Cabombaceae and Nymphaeaceae, makes it a fundamental root in defining character homology in Nuphar and the other genera. Consequently, our analyses provided strong statistical support for a monophyletic Nymphaeaceae, and resolutely confirmed the monophyly of Cabombaceae based on various data-partitioning schemes (Figure 6). In addition, the relationship between the five genera of Nymphaeaceae, Nuphar, Barclaya, Nymphaea, Euryale, and Victoria, was defined. Nuphar was placed at the base of the Nymphaeaceae family as a sister to Barclaya. These results are consistent with morphological circumscriptions of the family that places Nuphar at the basal position due to a lack of significant specialized features, synapomorphic for other Nymphaeaceae species [54,55]. Similarly, the clade consisting of Barclaya, Nymphaea, Euryale, and Victoria was strongly supported and congruent to Loehne et al. [19]. The relationship between the species of Nuphar corresponds to New World and Old World monophyletic subclades that were well-outlined and supported by both morphology and molecular datasets $[55,56]$.

The Barclaya genus, endemic to Southeast Asia, was previously classified under a monotypic family, Barclayaceae, based on morphological traits, but was later moved to Nymphaeaceae based on cladistics and molecular evidence [57]. Within Nymphaeaceae, Barclaya was confirmed to be a close relative of Nuphar [54], a position that was strongly supported by genome-scale plastid data in this study (100\%, ML and 1.0 PP, BI) under both partitioned and unpartitioned. Nymphaea, the largest and the most cosmopolitan genus within the family [58], has remained taxonomically challenging despite being accorded considerable attention. Although Borsch et al. [59] increased taxa sampling and improved molecular character sampling compared to the analysis done by Borsch et al. [59], certain nodes of Nymphaea subg. Nymphaea gained weak or lacked statistical support. In this study, a paraphyletic Nymphaea was strongly supported. However, certain internal nodes, such as the node linking N. jamesoniana and N. ampla, were moderately supported by ML analyses (BS $=79 \%$ and $94 \%$, unpartitioned and partitioned data, respectively) despite being strongly supported by the $\mathrm{BI}(\mathrm{PP}=1.0)$. The currently used chloroplast DNA dataset has the potential to resolve these nodes but, to achieve this, extensive taxon sampling is needed.

The relationship of Victoria and the monotypic genus Euryale has long been accepted and supported by a combination of molecular and morphological data $[54,60]$. These two genera are associated by their aculeate character; their leaves are shieldlike, with petioles inserted at the center of the leaf blades, but they are easily distinguished based on the shape of the leaf margin and the presence or absence of staminodia and carpellary appendages [58]. Their relationship was strongly confirmed in this study, although their connection to Nymphaea was only moderately supported. Previous investigations firmly positioned Victoria within Nymphaea [18]. The addition of Euryale slightly reduced that support, although their position within Nymphaea was maintained. Strong conclusions concerning the phylogenetic and evolutionary relationships between the Victoria-Euryale clade and Nymphaea can only be made after more plastid genome data are made available. 


\section{Materials and Methods}

\subsection{Plant Material and Genome Sequencing}

Fresh leaf samples of Nuphar pumila, N. shimadai, N. longifolia, and Euryale ferox were obtained from Wuhan Botanical Garden, Chinese Academy of Sciences, China, and voucher specimens were deposited in the Herbarium of the Wuhan Botanical Garden, Chinese Academy of Sciences (HIB). Leaf materials of Barclaya kunstleri were obtained from Bkt. Timah Natural Reserve, Singapore, and a voucher specimen was deposited in the Singapore Botanic Gardens Herbarium. About $5 \mathrm{~g}$ of fresh leaves per plant was collected and immediately dried with silica gel.

Total genomic DNA was isolated from $150 \mathrm{mg}$ of silica-dried leaf tissues with DNeasy Plant Mini Kits (Tiangen, Beijing, China) following the manufacturer's instructions. Approximately 5-10 $\mu \mathrm{g}$ of genomic DNA was used to construct paired-end sequencing libraries with insert sizes of between 250 and $350 \mathrm{bp}$ for each species. These libraries were then sequenced using the Illumina Hiseq 2500 platform (Illumina Inc., San Diego, CA, USA) to generate at least $5 \mathrm{~Gb}$ of $300 \mathrm{bp}$ paired-end read for all the species. The quality of the raw-sequence reads was checked using FastQC v0.11.2 (http:/ / www.bioinformatics.babraham.ac.uk/projects/fastqc/), where ambiguous and low-quality reads were discarded.

\subsection{Genome Assembly and Annotation}

A reference-guided strategy was used to assemble the chloroplast genomes. In order to identify and retrieve the chloroplast sequences, the filtered reads were mapped to two reference chloroplast genomes, Barclaya longifolia (KY_284156) [18] and Nuphar advena (NC_008788) [31], using Bowtie2 2.2.9 [61] with parameters D 15-R 2-N 1-L 22-i S,1,1.15. The extracted reads were assembled de novo using Velvet 1.2.10 [62] with the following settings: velveth $\mathrm{K}=79 \sim 105$ and velvetg cov_cutoff $=100$, resulting into 3-5 contigs. All contigs of each species were mapped to reference using GENEIOUS R8 (Biomatters Ltd., Auckland, New Zealand). The overlapping ends, 50-80 bp, were trimmed, while the gaps were filled by PCR amplification and Sanger sequencing using specifically designed primers. The positions of the single copies and the inverted-repeat regions were confirmed through self-blasting using Basic Local Alignment Search Tool (BLAST+). To verify the generated contigs, the reads were remapped to the complete chloroplast genomes using Bowtie2 2.2.9 with default parameters [61].

Each of the assembled chloroplast genomes was annotated using GeSeq [63] and Dual Organellar GenoMe Annotator (DOGMA) [64] using B. longifolia and N. advena as references. The annotations were manually corrected, wherever necessary, and verified using GENEIOUS R8 (Biomatters Ltd., Auckland, New Zealand) by realigning with the references. Finally, graphical circular gene maps for each of the species were constructed using OGDraw v1.2 [65]. The fully annotated chloroplast genomes were submitted to GenBank (accession numbers are shown in Table 1).

\subsection{Chloroplast Genome Comparisons}

In order to discover any significant interspecific and intergeneric variations among the newly generated chloroplast genome sequences of Nymphaeaceae, comparison analyses were carried out, focusing on various characters of the genomes, including sizes and gene content. The variations observed in chloroplast genome sizes are largely attributed to the contraction or expansion of the inverted regions. The four IR/SC borders of each of the chloroplast genomes of 12 species of Nymphaeaceae (five newly generated chloroplast genomes in this study and seven previous published chloroplast genomes: GenBank accession NC_008788, KU234277, KU189255, NC_024542, NC_031826, KY284156, and KY001813) and their adjacent genes were compared. Further, we used Mauve genome-alignment software [47] to conduct multiple genome-alignment analysis aiming at detecting any rearrangements or inversions within the chloroplast genomes of the 12 species of Nymphaeaceae. 


\subsection{Codon-Usage, RNA-Editing and Repetitive Sequences Analyses}

The annotations errors in Nymphaea jamesoniana, as highlighted by Gruenstaeudl et al. [18], were corrected, and genes ycf15 and ycf68 and the two open reading frames (orf42 and orf56) were excluded from these analyses. Nymphaea alba had two GenBank accessions, KU234277 and NC006050; we randomly picked KU234277 for these analyses. The frequency of synonymous codon usage, also referred to as CUB, was determined for all exons of 79 protein-coding genes in 12 species of Nymphaeaceae using MEGA Version 7 software [66]. The values of RSCU [67] were compared. Potential RNA-editing positions in the protein-coding genes of each chloroplast genome were predicted using Predictive RNA Editor for Plants (PREP) [68]. PREP uses 35 protein genes as reference to predict C-to-U editing events. The cut-off value was set at 0.8. MIcroSAtellite identification tool (MISA) [69] was used to search for SSR). The minimal repeat numbers were set at 10 for mono-, 5 for di-, 4 for tri-, and 3 for tetra-, penta-, and hexa-nucleotide repeat motifs. We used REPuter [70] to establish the size and location of direct, inverted, compliment, and reverse-repeat units in each of the chloroplast genomes of Nymphaeaceae. The lower limit of repeat size was set at $30 \mathrm{bp}$, with a repeat identity of $90 \%$ and a hamming distance of 3 .

\subsection{Phylogenetic Analyses}

All currently available complete chloroplast genome sequences of Nymphaeaceae, which represented four genera, were retrieved from GenBank (Table S1). Five new genomes were reported in this study, including a first for the Euryale genus. Chloroplast genome sequences of two genera of Cabombaceae, two species of Schisandraceae, two representatives of the monotypic Hydatellaceae family, and the monotypic genus Amborella were also obtained (Table S1). Several phylogenetic analyses using Amborella or Hydatellaceae as outgroup were conducted to determine the effects of outgroup selection on the taxonomic relationships within Nymphaeaceae and Cabombaceae.

Sixty-six protein-coding genes, common in all genome sequences, were extracted and aligned using the Muscle program [71]. The aligned sequences were concatenated, and topologies were constructed using ML and Bayesian Inference conducted in RAxML v.8.2.9 [72] and MrBayes v.3.2.5 [73]. The best-fitting nucleotide substitution models based on the Akaike information criterion were realized using jModeltest v.2.1.7 [74]. ML analyses were conducted using a GTR + G + I substitution model with 1000 bootstrap replicates. A heuristic search of 10 independent replicates was carried out for the ML analyses. BI analysis was done using the GTR $+\mathrm{G}$ model and, based on the Markov chain Monte Carlo (MCMC) algorithm, one million generations with four independent heated chains with sampling after every 1000 generations. Convergence was attained and operation stopped when the average standard deviation of split frequencies remained below 0.01 . The initial $25 \%$ of all sampled trees were discarded as burn-in, while the remaining $75 \%$ were used to construct a majority-rule consensus tree with posterior probabilities.

We conducted further phylogenetic analyses based on two different data partitions under ML and BI strategies. In the first phylogenetic analysis, we used jModeltest. v.2.1.7 [74] to infer the best-fitting substitution model for each of the 66 used genes. In this approach, each of the 66 genes was analyzed as a single partition. In the second analysis, the greedy-search algorithm executed in PartitionFinder2 [75] was used to determine the best model among the GTR, GTR + G, and GTR + I + G models based on the corrected selection criterion, the Aikaike Information Criterion (AICc).

\section{Conclusions}

Five newly sequenced complete chloroplast genomes of Nymphaeaceae, including the first in the Euryale genus, were reported. Comparative genomics revealed highly conserved patterns in relation to genome structure, nucleotide composition, and relative synonymous codon usage. However, minor variations were evident, particularly in the contraction/expansion of the inverted-repeat regions and in RNA-editing events, the majority of which appeared to be genus-specific, implying that each genus 
could have been subjected to unique evolutionary events. This study affirms the potential of chloroplast phylogenomics to solve taxonomic relationships within genera of Nymphaeaceae. By increasing taxa number and analyzing the validities of outgroups, a monophyletic Nymphaeaceae was attained, and the phylogenetic position of Nuphar was ascertained with strong statistical support. Nonetheless, there is need for further investigations to corroborate these findings.

Supplementary Materials: The following are available online at http://www.mdpi.com/1422-0067/19/12/ 3780 /s1. Figure S1. UPGMA dendrogram of the species of Nymphaeaceae, Cabombaceae, and Hydatellaceae constructed based on the events of RNA editing in the transcripts of 19 common protein-coding genes. Figure S2. Phylogenetic relationships of the species of Nymphaeales based on the (a) partitioned and (b) unpartitioned data scheme of 66 protein-coding genes. Amborella trichopoda was used as an outgroup. The numbers indicate ML bootstrap support (100) and BI posterior probabilities (1.0) values. The * symbol indicates maximum support. Table S1. Details of taxa used in phylogenetic analyses. Table S2. Details of codon usage and relative synonymous codon usage values of chloroplast genomes of 12 species of Nymphaeaceae. Table S3. Details of RNA-editing events, including genes whose transcripts were affected in each genome and the number of editing sites in each gene transcript. Table S4. Details of short and long repetitive sequences discovered in each of the chloroplast genomes of 12 species of Nymphaeaceae.

Author Contributions: J.C. and Q.W. designed the experiment; D.H., A.W.G., Z.L., J.M.N., and Y.G. assembled the sequences and revised the manuscript; D.H. and A.W.G. performed the experiments, analyzed the data, and wrote the paper; J.C. and Z.L. collected the plant materials. All authors have read and approved the final version of the manuscript.

Funding: This work was supported by the Strategic Priority Research Program of Chinese Academy of Sciences (Grant No. XDB31010000), the National Natural Science Foundation of China (No. 31570220), and the Wuhan Botanical Garden (CAS) (No. Y655261W03).

Acknowledgments: We thank Lua H.K., Ang W.F., and Bazilah M.I. from the Singapore Botanic Gardens Herbarium for collecting and sending the samples of Barclaya kunstleri, Josphat Kipng'etich Saina for his assistance in the data analyses and Michael Gruenstaeudl for his comments on the manuscript.

Conflicts of Interest: The authors declare no conflicts of interest.

\section{Abbreviations}

$\begin{array}{ll}\text { IR } & \text { Inverted repeat. } \\ \text { SSC } & \text { Small single copy. } \\ \text { LSC } & \text { Large single copy. } \\ \text { SSR } & \text { Simple sequence repeat. } \\ \text { PCGS } & \text { Protein-coding genes. } \\ \text { RNA } & \text { Ribonucleic acid } \\ \text { RSCU } & \text { Relative synonymous codon usage } \\ \text { CUB } & \text { Codon usage bias } \\ \text { UPGMA } & \text { Unweighted pair group method with arithmetic mean } \\ \text { ML } & \text { Maximum likelihoodBI Bayesian inference } \\ \text { PP } & \text { Posterior probability }\end{array}$

\section{References}

1. Delsuc, F.; Brinkmann, H.; Philippe, H. Phylogenomics and the reconstruction of the tree of life. Nat. Rev. Genet. 2005, 6, 361. [CrossRef] [PubMed]

2. Gitzendanner, M.A.; Soltis, P.S.; Wong, G.K.S.; Ruhfel, B.R.; Soltis, D.E. Plastid phylogenomic analysis of green plants: A billion years of evolutionary history. Am. J. Bot. 2018, 105, 291-301. [CrossRef] [PubMed]

3. Goremykin, V.V.; Nikiforova, S.V.; Biggs, P.J.; Zhong, B.; Delange, P.; Martin, W.; Woetzel, S.; Atherton, R.A.; Mclenachan, P.A.; Lockhart, P.J. The evolutionary root of flowering plants. Syst. Biol. 2013, 62, 50-61. [CrossRef] [PubMed]

4. Jansen, R.K.; Cai, Z.; Raubeson, L.A.; Daniell, H.; Leebens-Mack, J.; Müller, K.F.; Guisinger-Bellian, M.; Haberle, R.C.; Hansen, A.K.; Chumley, T.W. Analysis of 81 genes from 64 plastid genomes resolves relationships in angiosperms and identifies genome-scale evolutionary patterns. Proc. Natl. Acad. Sci. USA 2007, 104, 19369-19374. [CrossRef] [PubMed] 
5. Leebens-Mack, J.; Raubeson, L.A.; Cui, L.; Kuehl, J.V.; Fourcade, M.H.; Chumley, T.W.; Boore, J.L.; Jansen, R.K.; depamphilis, C.W. Identifying the basal angiosperm node in chloroplast genome phylogenies: Sampling one's way out of the Felsenstein zone. Mol. Biol. Evol. 2005, 22, 1948-1963. [CrossRef] [PubMed]

6. Luo, Y.; Ma, P.-F.; Li, H.-T.; Yang, J.-B.; Wang, H.; Li, D.-Z. Plastid phylogenomic analyses resolve Tofieldiaceae as the root of the early diverging monocot order Alismatales. Genome Biol. Evol. 2016, 8, 932-945. [CrossRef] [PubMed]

7. Moore, M.J.; Bell, C.D.; Soltis, P.S.; Soltis, D.E. Using plastid genome-scale data to resolve enigmatic relationships among basal angiosperms. Proc. Natl. Acad. Sci. USA 2007, 104, 19363-19368. [CrossRef] [PubMed]

8. Moore, M.J.; Soltis, P.S.; Bell, C.D.; Burleigh, J.G.; Soltis, D.E. Phylogenetic analysis of 83 plastid genes further resolves the early diversification of eudicots. Proc. Natl. Acad. Sci. USA 2010, 107, 4623-4628. [CrossRef] [PubMed]

9. Byng, J.W.; Chase, M.W.; Christenhusz, M.J.; Fay, M.F.; Judd, W.S.; Mabberley, D.J.; Sennikov, A.N.; Soltis, D.E.; Soltis, P.S.; Stevens, P.F. An update of the Angiosperm Phylogeny Group classification for the orders and families of flowering plants: APG IV. Bot. J. Linn. Soc. 2016, 181, 1-20.

10. Parkinson, C.L.; Adams, K.L.; Palmer, J.D. Multigene analyses identify the three earliest lineages of extant flowering plants. Curr. Biol. 1999, 9, 1485-1491. [CrossRef]

11. Soltis, P.S.; Soltis, D.E.; Chase, M.W. Angiosperm phylogeny inferred from multiple genes as a tool for comparative biology. Nature 1999, 402, 402. [CrossRef] [PubMed]

12. Borsch, T.; Hilu, K.W.; Wiersema, J.H.; Löhne, C.; Barthlott, W.; Wilde, V. Phylogeny of Nymphaea (Nymphaeaceae): Evidence from substitutions and microstructural changes in the chloroplast trnT-trnF region. Int. J. Plant Sci. 2007, 168, 639-671. [CrossRef]

13. Les, D.H.; Garvin, D.K.; Wimpee, C.F. Molecular evolutionary history of ancient aquatic angiosperms. Proc. Natl. Acad. Sci. USA 1991, 88, 10119-10123. [CrossRef] [PubMed]

14. Zimmer, E.A.; Qiu, Y.-L.; Endress, P.K.; Friis, E.M. Current perspectives on basal angiosperms: Introduction. Int. J. Plant Sci. 2000, 161, S1-S2. [CrossRef]

15. Friedman, W.E. Hydatellaceae are water lilies with gymnospermous tendencies. Nature 2008, $453,94$. [CrossRef] [PubMed]

16. Saarela, J.M.; Rai, H.S.; Doyle, J.A.; Endress, P.K.; Mathews, S.; Marchant, A.D.; Briggs, B.G.; Graham, S.W. Hydatellaceae identified as a new branch near the base of the angiosperm phylogenetic tree. Nature 2007, 446, 312. [CrossRef] [PubMed]

17. Biswal, D.K.; Debnath, M.; Kumar, S.; Tandon, P. Phylogenetic reconstruction in the Order Nymphaeales: ITS2 secondary structure analysis and in silico testing of Maturase K (matK) as a potential marker for DNA bar coding. Proc. BMC Bioinform. 2012, 13, S26.

18. Gruenstaeudl, M.; Nauheimer, L.; Borsch, T. Plastid genome structure and phylogenomics of Nymphaeales: Conserved gene order and new insights into relationships. Plant Syst. Evol. 2017, 303, 1251-1270. [CrossRef]

19. Loehne, C.; Borsch, T.; Wiersema, J.H. Phylogenetic analysis of Nymphaeales using fast-evolving and noncoding chloroplast markers. Bot. J. Linn. Soc. 2007, 154, 141-163. [CrossRef]

20. Nandi, O.I.; Chase, M.W.; Endress, P.K. A combined cladistic analysis of angiosperms using rbcL and non-molecular data sets. Ann. Mo. Bot. Gard. 1998, 137-214. [CrossRef]

21. Sokoloff, D.D.; Remizowa, M.V.; Macfarlane, T.D.; Rudall, P.J. Classification of the early-divergent angiosperm family Hydatellaceae: One genus instead of two, four new species and sexual dimorphism in dioecious taxa. Taxon 2008, 57, 179-200.

22. Christenhusz, M.J.; Byng, J.W. The number of known plants species in the world and its annual increase. Phytotaxa 2016, 261, 201-217. [CrossRef]

23. Daniell, H.; Lin, C.-S.; Yu, M.; Chang, W.-J. Chloroplast genomes: Diversity, evolution, and applications in genetic engineering. Genome Biol. 2016, 17, 134. [CrossRef] [PubMed]

24. Gruenstaeudl, M.; Gerschler, N.; Borsch, T. Bioinformatic workflows for generating complete Plastid genome sequences-An example from Cabomba (Cabombaceae) in the context of the phylogenomic analysis of the water-lily clade. Life 2018, 8, 25. [CrossRef] [PubMed]

25. Sun, Y.; Moore, M.J.; Zhang, S.; Soltis, P.S.; Soltis, D.E.; Zhao, T.; Meng, A.; Li, X.; Li, J.; Wang, H. Phylogenomic and structural analyses of 18 complete plastomes across nearly all families of early-diverging eudicots, including an angiosperm-wide analysis of IR gene content evolution. Mol. Phylogenet. Evol. 2016, 96, 93-101. [CrossRef] [PubMed] 
26. Xiao-Ming, Z.; Junrui, W.; Li, F.; Sha, L.; Hongbo, P.; Lan, Q.; Jing, L.; Yan, S.; Weihua, Q.; Lifang, Z. Inferring the evolutionary mechanism of the chloroplast genome size by comparing whole-chloroplast genome sequences in seed plants. Sci. Rep. 2017, 7, 1555. [CrossRef] [PubMed]

27. Graham, S.W.; Olmstead, R.G.; Barrett, S.C. Rooting phylogenetic trees with distant outgroups: A case study from the commelinoid monocots. Mol. Biol. Evol. 2002, 19, 1769-1781. [CrossRef] [PubMed]

28. Jansen, R.K.; Raubeson, L.A.; Boore, J.L.; dePamphilis, C.W.; Chumley, T.W.; Haberle, R.C.; Wyman, S.K.; Alverson, A.J.; Peery, R.; Herman, S.J. Section I-Comparing macromolecules: Exploring biological diversity-subsection C-the genomes-20 methods for obtaining and analyzing whole chloroplast genome sequences. Methods Enzymol. 2005, 395, 348-383.

29. Palmer, J.D. Plastid chromosomes: Structure and evolution. Mol. Biol. Plastids 1991, 7, 5-53.

30. Goremykin, V.V.; Hirsch-Ernst, K.I.; Wölfl, S.; Hellwig, F.H. Analysis of the Amborella trichopoda chloroplast genome sequence suggests that Amborella is not a basal angiosperm. Mol. Biol. Evol. 2003, 20, 1499-1505. [CrossRef] [PubMed]

31. Raubeson, L.A.; Peery, R.; Chumley, T.W.; Dziubek, C.; Fourcade, H.M.; Boore, J.L.; Jansen, R.K. Comparative chloroplast genomics: Analyses including new sequences from the angiosperms Nuphar advena and Ranunculus macranthus. BMC Genom. 2007, 8, 174. [CrossRef] [PubMed]

32. Chumley, T.W.; Palmer, J.D.; Mower, J.P.; Fourcade, H.M.; Calie, P.J.; Boore, J.L.; Jansen, R.K. The complete chloroplast genome sequence of Pelargonium $\times$ hortorum: Organization and evolution of the largest and most highly rearranged chloroplast genome of land plants. Mol. Biol. Evol. 2006, 23, 2175-2190. [CrossRef] [PubMed]

33. Wu, G. Amino acids: Metabolism, functions, and nutrition. Amino Acids 2009, 37, 1-17. [CrossRef] [PubMed]

34. Liu, G.; Wu, J.; Yang, H.; Bao, Q. Codon usage patterns in Corynebacterium glutamicum: Mutational bias, natural selection and amino acid conservation. Comp. Funct. Genom. 2010, 2010. [CrossRef] [PubMed]

35. Uddin, A. Indices of Codon Usage Bias. Proteom. Bioinform. 2017, 10, 6. [CrossRef]

36. Liu, Q.; Xue, Q. Comparative studies on codon usage pattern of chloroplasts and their host nuclear genes in four plant species. J. Genet. 2005, 84, 55-62. [CrossRef]

37. Zhou, M.; Long, W.; Li, X. Patterns of synonymous codon usage bias in chloroplast genomes of seed plants. For. Stud. China 2008, 10, 235. [CrossRef]

38. Schmitz-Linneweber, C.; Barkan, A. RNA splicing and RNA editing in chloroplasts. In Cell and Molecular Biology of Plastids; Springer: Berlin/Heidelber, Germany, 2007; pp. 213-248.

39. Sugiura, M. RNA editing in chloroplasts. In RNA Editing; Springer: Berlin/Heidelber, Germany, 2008; pp. 123-142.

40. Freyer, R.; Kiefer-Meyer, M.-C.; Kössel, H. Occurrence of plastid RNA editing in all major lineages of land plants. Proc. Natl. Acad. Sci. USA 1997, 94, 6285-6290. [CrossRef] [PubMed]

41. Li, Y.C.; Korol, A.B.; Fahima, T.; Beiles, A.; Nevo, E. Microsatellites: Genomic distribution, putative functions and mutational mechanisms: A review. Mol. Ecol. 2002, 11, 2453-2465. [CrossRef] [PubMed]

42. Gandhi, S.G.; Awasthi, P.; Bedi, Y.S. Analysis of SSR dynamics in chloroplast genomes of Brassicaceae family. Bioinformation 2010, 5, 16. [CrossRef] [PubMed]

43. De Las Rivas, J.; Lozano, J.J.; Ortiz, A.R. Comparative analysis of chloroplast genomes: Functional annotation, genome-based phylogeny, and deduced evolutionary patterns. Genome Res. 2002, 12, 567-583. [CrossRef] [PubMed]

44. Downie, S.R.; Jansen, R.K. A comparative analysis of whole plastid genomes from the Apiales: Expansion and contraction of the inverted repeat, mitochondrial to plastid transfer of DNA, and identification of highly divergent noncoding regions. Syst. Bot. 2015, 40, 336-351. [CrossRef]

45. Wang, R.J.; Cheng, C.L.; Chang, C.C.; Wu, C.L.; Su, T.M.; Chaw, S.M. Dynamics and evolution of the inverted repeat-large single copy junctions in the chloroplast genomes of monocots. BMC Evol. Biol. 2008, 8, 36. [CrossRef] [PubMed]

46. Plunkett, G.M.; Downie, S.R. Expansion and contraction of the chloroplast inverted repeat in Apiaceae subfamily Apioideae. Syst. Bot. 2000, 648-667. [CrossRef]

47. Darling, A.C.; Mau, B.; Blattner, F.R.; Perna, N.T. Mauve: Multiple alignment of conserved genomic sequence with rearrangements. Genome Res. 2004, 14, 1394-1403. [CrossRef] [PubMed]

48. Clegg, M.T.; Gaut, B.S.; Learn, G.H.; Morton, B.R. Rates and patterns of chloroplast DNA evolution. Proc. Natl. Acad. Sci. USA 1994, 91, 6795-6801. [CrossRef] [PubMed] 
49. Jian, S.; Soltis, P.S.; Gitzendanner, M.A.; Moore, M.J.; Li, R.; Hendry, T.A.; Qiu, Y.-L.; Dhingra, A.; Bell, C.D.; Soltis, D.E. Resolving an ancient, rapid radiation in Saxifragales. Syst. Biol. 2008, 57, 38-57. [CrossRef] [PubMed]

50. Borsch, T.; Löhne, C.; Wiersema, J. Phylogeny and evolutionary patterns in Nymphaeales: Integrating genes, genomes and morphology. Taxon 2008, 57, 1052.

51. Wheeler, W.C. Nucleic acid sequence phylogeny and random outgroups. Cladistics 1990, 6, 363-367. [CrossRef]

52. Goremykin, V.; Hirsch-Ernst, K.; Wölfl, S.; Hellwig, F. The chloroplast genome of the "basal” angiosperm Calycanthus fertilis-structural and phylogenetic analyses. Plant Syst. Evol. 2003, 242, 119-135. [CrossRef]

53. Stefanović, S.; Rice, D.W.; Palmer, J.D. Long branch attraction, taxon sampling, and the earliest angiosperms: Amborella or monocots? BMC Evol. Biol. 2004, 4, 35. [CrossRef] [PubMed]

54. Les, D.H.; Schneider, E.L.; Padgett, D.J.; Soltis, P.S.; Soltis, D.E.; Zanis, M. Phylogeny, classification and floral evolution of water lilies (Nymphaeaceae; Nymphaeales): A synthesis of non-molecular, rbcL, matK, and $18 \mathrm{~S}$ rDNA data. Syst. Bot. 1999, 28-46. [CrossRef]

55. Padgett, D.J. A monograph of Nuphar (Nymphaeaceae). Rhodora 2007, 109, 1-95. [CrossRef]

56. Padgett, D.J.; Les, D.H.; Crow, G.E. Phylogenetic relationships in Nuphar (Nymphaeaceae): Evidence from morphology, chloroplast DNA, and nuclear ribosomal DNA. Am. J. Bot. 1999, 86, 1316-1324. [CrossRef] [PubMed]

57. Williamson, P.S.; Schneider, E.L. Floral aspects of Barclaya (Nymphaeaceae): Pollination, ontogeny and structure. In Early Evolution of Flowers; Springer: Vienna, Austria, 1994; pp. 159-173.

58. Schneider, E.; Williamson, P. Nymphaeaceae. In Flowering Plants · Dicotyledons: Magnoliid, Hamamelid and Caryophyllid Families; Kubitzki, K., Rohwer, J.G., Bittrich, V., Eds.; Springer: Berlin/Heidelber, Germany, 1993; pp. 486-493.

59. Borsch, T.; Wiersema, J.H.; Hellquist, C.B.; Löhne, C.; Govers, K. Speciation in North American water lilies: Evidence for the hybrid origin of the newly discovered Canadian endemic Nymphaea loriana sp. nov.(Nymphaeaceae) in a past contact zone. Botany 2014, 92, 867-882. [CrossRef]

60. Thorne, R.F. Classification and geography of the flowering plants. Bot. Rev. 1992, 58, 225-327. [CrossRef]

61. Langmead, B.; Salzberg, S.L. Fast gapped-read alignment with Bowtie 2. Nat. Methods 2012, 9, 357. [CrossRef] [PubMed]

62. Zerbino, D.; Birney, E. Velvet: Algorithms for de novo short read assembly using de Bruijn graphs. Genome Res. 2008. [CrossRef] [PubMed]

63. Tillich, M.; Lehwark, P.; Pellizzer, T.; Ulbricht-Jones, E.S.; Fischer, A.; Bock, R.; Greiner, S. GeSeq-versatile and accurate annotation of organelle genomes. Nucleic Acids Res. 2017, 45, W6-W11. [CrossRef] [PubMed]

64. Wyman, S.K.; Jansen, R.K.; Boore, J.L. Automatic annotation of organellar genomes with DOGMA. Bioinformatics 2004, 20, 3252-3255. [CrossRef] [PubMed]

65. Lohse, M.; Drechsel, O.; Bock, R. OrganellarGenomeDRAW (OGDRAW): A tool for the easy generation of high-quality custom graphical maps of plastid and mitochondrial genomes. Curr. Genet. 2007, 52, 267-274. [CrossRef] [PubMed]

66. Kumar, S.; Stecher, G.; Tamura, K. MEGA7: Molecular evolutionary genetics analysis version 7.0 for bigger datasets. Mol. Biol. Evol. 2016, 33, 1870-1874. [CrossRef] [PubMed]

67. Sharp, P.M.; Li, W.-H. The codon adaptation index-a measure of directional synonymous codon usage bias, and its potential applications. Nucleic Acids Res. 1987, 15, 1281-1295. [CrossRef] [PubMed]

68. Mower, J.P. The PREP suite: Predictive RNA editors for plant mitochondrial genes, chloroplast genes and user-defined alignments. Nucleic Acids Res. 2009, 37, W253-W259. [CrossRef] [PubMed]

69. Beier, S.; Thiel, T.; Münch, T.; Scholz, U.; Mascher, M. MISA-web: A web server for microsatellite prediction. Bioinformatics 2017, 33, 2583-2585. [CrossRef] [PubMed]

70. Kurtz, S.; Choudhuri, J.V.; Ohlebusch, E.; Schleiermacher, C.; Stoye, J.; Giegerich, R. REPuter: The manifold applications of repeat analysis on a genomic scale. Nucleic Acids Res. 2001, 29, 4633-4642. [CrossRef] [PubMed]

71. Edgar, R.C. MUSCLE: Multiple sequence alignment with high accuracy and high throughput. Nucleic Acids Res. 2004, 32, 1792-1797. [CrossRef] [PubMed]

72. Stamatakis, A. RAxML version 8: A tool for phylogenetic analysis and post-analysis of large phylogenies. Bioinformatics 2014, 30, 1312-1313. [CrossRef] [PubMed] 
73. Ronquist, F.; Huelsenbeck, J.P. MrBayes 3: Bayesian phylogenetic inference under mixed models. Bioinformatics 2003, 19, 1572-1574. [CrossRef] [PubMed]

74. Darriba, D.; Taboada, G.L.; Doallo, R.; Posada, D. jModelTest 2: More models, new heuristics and parallel computing. Nat. Methods 2012, 9, 772. [CrossRef] [PubMed]

75. Lanfear, R.; Frandsen, P.B.; Wright, A.M.; Senfeld, T.; Calcott, B. PartitionFinder 2: New methods for selecting partitioned models of evolution for molecular and morphological phylogenetic analyses. Mol. Biol. Evol. 2017, 34, 772-773. [CrossRef] [PubMed] 